\title{
Hysterosalpingogram findings among subfertile women undergoing assisted reproductive technology
}

\author{
Dania Al-Jaroudi' \\ Abeer Abdullah \\ Aldughayyim² \\ Wadha Suliman Alshamry ${ }^{3}$ \\ Ahlam Saud Alrashidi ${ }^{3}$ \\ Ahmed A Bahnassy ${ }^{4}$ \\ 'Reproductive Endocrine and \\ Infertility Medicine Department, King \\ Fahad Medical City, Riyadh, Saudi \\ Arabia; ${ }^{2} \mathrm{AL}$ Maarefa College King \\ Khaled Branch, Ad Diriyah for Science \\ and Technology MCST, Riyadh, Saudi \\ Arabia; ${ }^{3}$ Faculty of Medicine, King \\ Khalid Hospital, Hail, Saudi Arabia; \\ ${ }^{4}$ Faculty of Medicine, King Fahad \\ Medical City, Riyadh, Saudi Arabia
}

Correspondence: Dania Al-Jaroudi Women's Specialized Hospital Reproductive, Endocrine and Infertility Medicine Department, King Fahad Medical City, Riyadh, Saudi Arabia Tel +966 I2889999 ext 21100 Email daljaroudi@kfmc.med.sa
This article was published in the following Dove Press journal: International Journal of Women's Health

Purpose: The objectives of our study included comparing reproductive histories and causes of infertility between patients with and without a hysterosalpingogram (HSG) investigation, and summarizing the prevalence and extent of tubal abnormalities among patients who underwent HSG. Outcomes following assisted reproductive technology (ART) were compared between HSG and non-HSG groups.

Materials and methods: A cross-sectional study was conducted to review the medical records of 200 Saudi women with subfertility. In addition to information on HSG, patient data extracted included age, body mass index (BMI), infertility duration, miscarriage experience, parity, cause of infertility, and history of previous surgery, ectopic pregnancy, endometriosis, tubal surgery, pelvic inflammatory disease (PID), in vitro fertilization (IVF), intracytoplasmic sperm injection (ICSI), pregnancy, and live birth.

Results: One hundred and ninety six $(98.0 \%)$ patients had either IVF $(n=18 ; 9.0 \%)$ or ICSI $(\mathrm{n}=178 ; 89.0 \%)$ performed; ICSI was performed in $157(90 \%)$ and $21(81 \%)$ patients. Of the 12 women with tubal factor who did not undergo HSG, $3(25.0 \%)$ became pregnant after ART, $8(66.7 \%)$ did not, and the status of $1(8.3 \%)$ is yet unknown.

Conclusions: Our study aimed to contribute to resolving the debate regarding the continuing role of HSG in an environment where ART has become established as a successful approach to treat infertility. Most of the HSGs were done as per the attending physician's discretion, and not according to any specific policy.

Keywords: assisted reproductive technology, hysterosalpingogram, intracytoplasmic sperm injection, infertility, in vitro fertilization

\section{Introduction}

The worldwide prevalence of infertility, defined as failure to conceive after more than 12 months of unprotected intercourse, is approximately $8 \%-12 \% .^{1-3}$ Subfertility, or a decreased ability to conceive, affects an additional $15 \%$ of couples. Compromised fallopian tube patency and function and endometriosis are responsible for $25 \%-33 \%$ of interrupted fertility. ${ }^{4}$ Tubal occlusion can be congenital, spasmodic, or as the result of infection, polyps, and fibroids; ${ }^{5}$ it can be uni- or bilateral; and located distally, midsegment, or proximally. ${ }^{4}$ Tubal factor infertility has disparate prevalence geographically, accounting for over $85 \%$ of women infertility in sub-Saharan Africa compared with 33\% worldwide. $^{6}$

Imaging has an important role in the diagnostic evaluation of infertility, including tubal patency. ${ }^{7}$ Transvaginal ultrasound (TVUS) is often used for first-line imaging, ${ }^{6,8}$ followed by hysterosalpingosonography with contrast to evaluate abnormal findings. ${ }^{9}$ A hysterosalpingogram (HSG) is an X-ray visualization of the lumen of the uterus and 
fallopian tubes, which can detect abnormalities including blockage, polyps, and salpingitis isthmica nodosa (SIN) in the fallopian tube and uterine cavity. ${ }^{10-12}$ HSG is inexpensive and uncomplicated, which has contributed to its acquiring a primary role in assessing abnormal TVUS findings in the fallopian tube and uterine cavity. ${ }^{13-15}$

Several current guidelines include HSG as part of standard fertility screening in women without comorbidities such as pelvic inflammatory disease (PID), previous ectopic pregnancy, or endometriosis; in which case laparoscopy and dye are recommended, to allow concomitant assessment of tubal and pelvic pathology. ${ }^{16}$ Several centers include HSG as a standard part of the infertility workup for all consenting women. ${ }^{17}$

The utility of HSG has recently been questioned in the setting of increasing pregnancy rates achieved in infertile women following assisted reproductive technology (ART), providing an alternative route to achieve pregnancy that may obviate the need for surgical repair of damaged tubes. In addition, other procedures are available for assessing tubal patency that are reported to have greater sensitivity and acceptability compared with HSG. ${ }^{15}$ Accordingly, although HSG has been a valuable tool for diagnosing tubal defects, its continuing role in patients undergoing ART has become a subject of debate.

The objective of our ongoing study is to assess the use and benefit of HSG in a tertiary care infertility clinic in Riyadh, Saudi Arabia, where HSG policies are not in place. HSG is performed according to the attending physician's discretion, which does not follow specific guidelines describing patients for whom HSG is indicated. However, since our hospital is a referral center, most of our patients would have had an HSG in another hospital. Accordingly, the study objectives include comparing reproductive histories and causes of infertility between patients with and without an HSG investigation, and summarizing the prevalence and extent of tubal abnormalities among patients who underwent HSG. Outcomes following ART will be compared between HSG and non-HSG groups. This preliminary report summarizes data from 200 consecutive patients seen in an 18-month period.

\section{Materials and methods}

A cross-sectional study, approved by the King Fahad Medical City (KFMC) institutional review board (IRB), was undertaken to review the medical records of Saudi women with subfertility who were attending the Reproductive Endocrine and Infertility Medicine Department (REIMD) ART clinics in the KFMC, Women's Specialized Hospital, Riyadh, Saudi Arabia, between January 2015 and June 2016. Although record retrieval required access to identifiers, the study records and analysis database was anonymized. Since the study is retrospective, as per our institution policy, only IRB approval is needed before conducting the study. Patient consent was waived as no patient identifiers were obtained. In addition to information on HSG, patient data extracted included age, body mass index (BMI), infertility duration, miscarriage experience, parity, cause of infertility, and history of previous surgery, ectopic pregnancy, endometriosis, tubal surgery, PID, in vitro fertilization (IVF), intracytoplasmic sperm injection (ICSI), pregnancy, and live birth.

Data were summarized, and numerical differences between patient subgroups were visualized using appropriate graphics. Data were entered and analyzed using SPSS ver. 22. Quantitative data were represented as mean $\pm \mathrm{SD}$, while qualitative ones were described as frequencies and percentages. Chi-square test was used to find any association between qualitative variables, while t-test or ANOVA was used to find any mean differences for quantitative variables among the groups as appropriate. $\mathrm{P}$ value was set to be $<0.05$ throughout the study.

\section{Results}

The 200 women who attended the ART clinics during this study interval had a mean age of $31.8 \pm 5.0$ years (range 23-41), BMI of 30.1 \pm 4.5 (range 19-37), and infertility duration of $6.1 \pm 4.2$ years (range 1-19). Male factor was the most common cause of infertility ( $\mathrm{n}=54 ; 27.0 \%)$; while endometriosis was the least common cause $(n=5 ; 2.5 \%)$ (Table 1$)$. More than one-half $(\mathrm{n}=116 ; 58.0 \%)$ had primary infertility.

Table I Patient characteristics

\begin{tabular}{|c|c|c|c|}
\hline & $\begin{array}{l}\text { No HSG } \\
(n=\mid 74)\end{array}$ & $\begin{array}{l}\text { HSG } \\
(n=26)\end{array}$ & $\begin{array}{l}\text { Total } \\
(\mathrm{N}=\mathbf{2 0 0})\end{array}$ \\
\hline Age, mean years (SD) & $33.0(5.2)$ & $31.8(5.0)$ & $32.8(5.1)$ \\
\hline BMI, mean (SD) & $29.0(5.1)$ & $30.1(4.5)$ & $29.1(5.1)$ \\
\hline Primary infertility, n (\%) & $103(59.2)$ & $13(50.0)$ & $116(58.0)$ \\
\hline Duration of infertility, mean years (SD) & $6.8(4.4)$ & $6.1(4.2)$ & $6.7(4.4)$ \\
\hline \multicolumn{4}{|l|}{ Cause of infertility, $n$ (\%) } \\
\hline Other & $2(1.1)$ & $0(0.0)$ & $2(1.0)$ \\
\hline Unexplained & $35(20.1)$ & $7(26.9)$ & $42(21.0)$ \\
\hline Anovulation & $10(5.7)$ & $3(11.5)$ & $13(6.5)$ \\
\hline Male factor & $49(28.2)$ & $5(19.2)$ & $54(27.0)$ \\
\hline Endometriosis & $5(2.9)$ & $0(0.0)$ & $5(2.5)$ \\
\hline PCOS & $21(12.1)$ & $2(7.7)$ & $23(11.5)$ \\
\hline Tubal & $12(6.9)$ & I (3.8) & $13(6.5)$ \\
\hline Multiple & $40(23.0)$ & $8(30.8)$ & $48(24.0)$ \\
\hline \multicolumn{4}{|c|}{ Reproductive pathology/procedure history, n (\%) } \\
\hline Surgery & $32(18.4)$ & $6(23.1)$ & $38(19.0)$ \\
\hline Ectopic pregnancy & $14(8.0)$ & $3(11.5)$ & $17(8.5)$ \\
\hline Endometriosis & $6(3.4)$ & $0(0.0)$ & $6(3.0)$ \\
\hline Tubal surgery & $8(4.6)$ & $3(11.5)$ & $11(5.5)$ \\
\hline PID & $3(1.7)$ & $0(0.0)$ & $3(1.5)$ \\
\hline
\end{tabular}

Abbreviations: HSG, hysterosalpingogram; BMI, body mass index; PCOS, polycystic ovary syndrome; PID, pelvic inflammatory disease. 
Table 2 Causes of infertility and previous history in patients who underwent HSG (N=26)

\begin{tabular}{|c|c|c|c|c|c|c|c|}
\hline \multirow[t]{2}{*}{ All HSG } & Unexplained & Anovulation & Male factor & PCOS & Tubal & Multiple & Total \\
\hline & 7 (26.9) & 3 (II.5) & $5(19.2)$ & $2(7.7)$ & I (3.8) & $8(30.8)$ & 26 \\
\hline Normal & $6(85.7)$ & I (33.3) & $3(60.0)$ & $2(100.0)$ & $(0.0)$ & $2(25.0)$ & $14(53.8)$ \\
\hline Bilateral & $(0.0)$ & I (33.3) & I (20.0) & $(0.0)$ & I (I00.0) & I (12.5) & $4(15.4)$ \\
\hline Left & I (I4.3) & I (33.3) & I (20.0) & $(0.0)$ & $(0.0)$ & $2(25.0)$ & $5(19.2)$ \\
\hline Right & $(0.0)$ & $(0.0)$ & $(0.0)$ & $(0.0)$ & $(0.0)$ & $3(37.5)$ & $3(1 \mathrm{l} .5)$ \\
\hline
\end{tabular}

Abbreviations: HSG, hysterosalpingogram; PCOS, polycystic ovary syndrome.

HSG was performed in $26(13.0 \%)$ women and this was according to the attending physician's discretion. Of 13 women in the entire cohort (6.5\%) who had infertility due to tubal factor, only 1 underwent HSG (Table 2). Among the 26 women with HSG, 14 (53.8\%) had normal results. Bilateral, left, and right block were noted in 4 (15.4\%), 5 (19.2\%), and 3 (11.5\%) patients, respectively. No follow-up procedures were performed on patients with uni- or bilateral blocked tubes. Additionally, pre-HSG known tubal factors were noted as the cause of infertility for 12 who did not have HSG performed and 1 who did.

In the entire cohort, $196(98.0 \%)$ patients had either IVF $(\mathrm{n}=18 ; 9.0 \%)$ or ICSI $(\mathrm{n}=178 ; 89.0 \%)$ performed. Procedures were canceled for 4 patients. IVF was used in $14(8.0 \%)$ of non-HSG and $4(15.4 \%)$ HSG patients; and CSI was performed in 157 (90\%) of non-HSG group and in $21(81 \%)$ in the HSG group.

Currently, pregnancy information for $17 \%$ of IVF and $26 \%$ of ICSI patients remains unconfirmed; however, the 4 patients with bilateral tubal block were pregnant following $\operatorname{IVF}(n=2)$ and ICSI $(n=2)$. The cause of infertility in these 4 pregnant women was anovulation $(n=1)$, male factor $(n=1)$, and multiple causes $(\mathrm{n}=1)$, as well as the single patient with tubal factor infertility who underwent HSG. Of the 12 women with tubal factor who did not undergo HSG, 3 (25.0\%) became pregnant after ART, $8(66.7 \%)$ did not, and the status of $1(8.3 \%)$ is yet unknown. Two of the 3 women with a history of ectopic pregnancy who underwent ART after HSG became pregnant, including 1 with bilateral block and male factor infertility, and 1 with normal tubes and unexplained infertility. The third patient, who did not become pregnant after ART, had unilateral left block and unexplained infertility.

\section{Discussion}

HSG was performed on $13.0 \%$ of patients attending the KFMC ART clinics during the period under study. None of our 26 patients who underwent HSG had a history of PID or endometriosis, consistent with NICE guidelines. ${ }^{16}$ However, $3(11.5 \%)$ had a history of ectopic pregnancy, which precludes an HSG indication according to those guidelines.
The rationale and benefit of performing the procedure in these patients are particularly questionable. A report from Oman noted that all consenting women who present to the subfertility clinic are evaluated by HSG. ${ }^{15,17}$ This retrospective study of 218 women who underwent HSG included 3 with a history of PID and 16 with a history of ectopic pregnancy. Compared with the $46 \%$ of patients in our small sample with any block and $15.4 \%$ with bilateral block, the Oman study reported that $23 \%$ of patients had any blockage shown by HSG, and $2.8 \%$ had bilateral block. Laparoscopy was performed for 4 of the 6 bilateral block cases, which confirmed the HSG results.

A retrospective study in Saudi Arabia observed an unusually high prevalence of tubal disorders diagnosed by HSG, reporting that $81 \%$ of 117 women had tubal blockage diagnosed by HSG, including $27 \%$ with bilateral block. ${ }^{18}$ The authors state that their study confirms that HSG should continue to be part of first-line infertility investigations; however, no data were presented to support the accuracy of the HSG diagnoses. In addition, the cases were women who underwent HSG between 2007 and 2012, yet no patient follow-up or outcome data were included in the 2016 publication. Accordingly, the value of HSG was not demonstrated in that report.

Several reports note that HSG may not be as reliable as other procedures for investigating tubal patency. In one report, HSG was accused of being "out of date," and should no longer be used for infertility evaluation. ${ }^{19}$ Others believe HSG is more appropriately considered a screening rather than a diagnostic test. ${ }^{20}$ That is, HSG can be used to determine whether further tubal testing is indicated. An individual patient meta-analysis of 4,521 women from 7 studies concluded that HSG is a useful tubal patency screening test for all infertile couples, with pooled sensitivity and specificity of 53\% and $87 \%$ for any tubal pathology, and $46 \%$ and $95 \%$ for bilateral tubal pathology. ${ }^{21}$ However, this conclusion has been challenged, questioning the assumption that a moderate specificity is useful in a setting with barely $50 \%$ sensitivity. ${ }^{22}$ Despite reports that HSG is reliable for revealing tubal occlusion but not patency, ${ }^{23}$ up to $60 \%$ of cases diagnosed with 
tubal obstruction using HSG have been shown via laparoscopy to have patent fallopian tubes. ${ }^{24-26}$ In one study, $80 \%$ of 40 patients with an HSG diagnosis of bilateral proximal obstruction were subsequently shown using sonohysterography to have at least one patent tube. ${ }^{27}$ In another study, 511 patients had both HSG and laparoscopy performed. ${ }^{28}$ In 153 patients where HSG showed 1-sided occlusion, 60\% showed no occlusion on laparoscopy. In addition, no occlusion was observed laparoscopically in $44 \%$ of 82 patients diagnosed with bilateral occlusion on HSG. Conversely, no occlusions were shown using HSG in almost a quarter of patients who had unilateral $(22 \%)$ or bilateral $(23 \%)$ occlusion on laparoscopy. An important limitation of that study was the different timing of the two investigations, which were separated by several months. ${ }^{28}$

The value of identifying tubal pathology for a patient who qualifies for ART has been questioned in the setting where monthly fecundity following ART greatly exceeds that achieved after surgical repair of the fallopian tubes. ${ }^{4}$ Robotic-assisted laparoscopic midsegment reanastomosis, most commonly performed for women who regret surgical sterilization, has allowed cumulative pregnancy rates similar to IVF; however, the required postsurgical wait before attempting pregnancy delays outcomes.

The value of unilateral patency results has been questioned, with the suggestion that the media may only go through one tube even in a setting of bilateral patency, taking the "path of least resistance." ${ }^{24}$ In addition, the clinical relevance of unilateral tubal occlusion is uncertain, as similar conception rates have been reported in women with and without a single blocked tube diagnosed by HSG and laparoscopy. ${ }^{28,29}$ The probability of a natural conception was nonsignificantly reduced by $20 \%$ in 322 patients with either unilateral impaired flow or unilateral occlusion diagnosed using HSG, compared with the conception rate for 2,097 women with bilateral normal HSG findings. These authors believe that HSG provides a beneficial investigation in women without comorbidities, as recommended in the NICE guidelines. ${ }^{16}$ They noted that tubal flushing with oil-soluble contrast medium has been associated with improved pregnancy rates, with a review of 13 randomized control trials suggesting that subfertile women with a $17 \%$ chance of ongoing pregnancy with no intervention could increase their chance of pregnancy to $29 \%-55 \%$ after tubal flushing with oil-based contrast media. ${ }^{30}$

Pregnancy rates following IVF have been lower in cases with hydrosalpinx, with a concomitant increased rate of miscarriage and ectopic pregnancy, which has been theorized to be due to an adverse effect of hydrosalpingeal fluid that accesses the uterine cavity. ${ }^{31}$ Accordingly, proximal occlusion of the hydrosalpinx has been reported to increase pregnancy rates when compared to patients who did not undergo this procedure prior to IVF. However, HSG was reported over 20 years ago to have poor accuracy for diagnosing distal obstruction, and absence of hydrosalpinx and adhesions. ${ }^{29}$ Accordingly, although hysteroscopic tubal occlusion can be successfully performed in the physician's office, laparoscopy should be considered the first-line approach to confirm the diagnosis of hydrosalpinx, avoiding iatrogenic obstruction of fallopian tubes that were misdiagnosed as hydrosalpinx using HSG. ${ }^{16}$

HSG is relatively safe; however, it has been reported to cause considerable stress and anxiety to the patient both before and during the procedure, which may be reduced by pre-procedure education and counseling. ${ }^{32}$ Pain is a common adverse reaction, ${ }^{33}$ which may be due to cervical grasping, patient sensitivity, injection hydrostatic pressure, and peritoneal irritation. ${ }^{34}$ In one study, less pain was experienced by women with bilateral tube obstruction, possibly related to absence of contrast media induced peritoneal irritation. ${ }^{34}$

It is clear that more data are needed on the current role of HSG in fertility management. Few reports include details regarding patient selection for $\mathrm{HSG}$, and little outcome data are available.

Our study aims to contribute to resolving the debate regarding the continuing role of $\mathrm{HSG}$ in an environment where ART has become established as a successful approach to treat infertility in a selected group of patients. ${ }^{25}$ Our patients were mostly referred from different hospitals for treating infertility. This might explain the lack of requests to do HSG and to immediately book for ART instead. Most of the HSGs were done as per the attending physician's discretion, and not according to any specific policy or guideline. However, tubal patency testing is recommended for infertile patients in the initial step of diagnosis by most professional societies in the field, based on general consensus and available evidence. ${ }^{16,35}$ Having said that, HSG remains an important diagnostic tool for patients with infertility since there is a groundswell of high-level opinion that IVF is overutilized and that many women can become pregnant following investigations including HSG which reveal unexplained infertility. ${ }^{35}$ This study calls for a review of guidelines and policies and revision of the IVF physicians' practices.

\section{Acknowledgments}

The authors would like to thank Dr Mohammad Al Tannir, for his guidance from the research center, and Dr Valerie 
Zimmerman for her assistance in proof reading the article. Dania Al-Jaroudi, Abeer Abdullah Aldughayyim, Wadha Suliman Alshamry, Ahlam Saud Alrashidi, and Ahmad A Bahnasy declared that King Fahad Medical City paid the manuscript fees and funded the study.

The research project has been approved as suitable by the institutional review board at KFMC approved on July 2016 IRB-log 16-229.

\section{Disclosure}

The authors report no conflicts of interest in this work.

\section{References}

1. Gnoth C, Godehardt E, Frank-Herrmann P, Friol K, Tigges J, Freundl G. Definition and prevalence of subfertility and infertility. Hum Reprod. 2005;20(5):1144-1147.

2. Reproductive Health Outlook. Infertility: Overview/lessons learned, 1997-2005. Available from: http://www.rho.org. Accessed January 6, 2017.

3. Inhorn MC. Global infertility and the globalization of new reproductive technologies: illustrations from Egypt. Soc Sci Med. 2003;56(9): 1837-1851.

4. Sotrel G. Is surgical repair of the fallopian tubes ever appropriate? Rev Obstet Gynecol. 2009;2(3):176-185.

5. Dun EC, Nezhat CH. Tubal factor infertility: diagnosis and management in the era of assisted reproductive technology. Obstet Gynecol Clin North Am. 2012;39(4):551-566.

6. Pundir J, El Toukhy T. Uterine cavity assessment before IVF. Womens Health. 2010;6(6):841-848.

7. Steinkeler JA, Woodfield CA, Lazarus E, Hillstrom MM. Female infertility: a systematic approach to radiologic imaging and diagnosis. Radiographics. 2009;29(5):1353-1370.

8. Onwuchekwa CR, Oriji VK. Hysterosalpingographic (HSG) Pattern of Infertility in Women of Reproductive Age. J Hum Reprod Sci. 2017;10(3):178-184.

9. Adrian CS, Nikola F, Cornelia U, Urech-Ruth C, Hohl Mk K-H. Hysterosalpingography in the work-up of female infertility: indications, technique, and diagnostic findings. Insights Imaging. 2013;3(5):475-483.

10. Ott DJ, Fayez JA, Chen MYM. Techniques of hysterosalpingography. In: Ott DJ, Fayez JA, Zagoria RJ, eds. Hysterosalpingography: A Text and Atlas. 2nd ed. Baltimore: MD: Williams \& Wilkins; 1998:11-27.

11. Khalaf Y. Tubal subfertility. BMJ. 2003;327(7415):610-613.

12. Mitchell AWM. Allison \& Grainger's Diagnostic Radiology. 4th ed. Vol. 3; Edinburgh: Churchill-Livingstone; 2001:2227-2235.

13. Khan K, Gupta JK, Mires G. Core Clinical Cases in Obstetrics and Gynaecology: A Problem-Solving Approach. Vol. 152. London: Hodder Arnold; 2005.

14. Brown SE, Coddington CC, Schnorr J, Toner JP, Gibbons W, Oehninger S. Evaluation of outpatient hysteroscopy, saline infusion hysterosonography, and hysterosalpingography in infertile women: a prospective, randomized study. Fertil Steril. 2000;74(5):1029-1034.

15. Imaoka I, Wada A, Matsuo M, Yoshida M, Kitagaki H, Sugimura K. MR imaging of disorders associated with female infertility: use in diagnosis, treatment, and management. Radiographics. 2003;23(6):1401-1421.

16. National Institute for Health and Clinical Excellence. Fertility: assessment and treatment for people with fertility problems. NICE Clinical Guideline 156; 2013. Available from: http://guidance.nice. org.uk/cg156. Accessed July 08, 2017.
17. Al Subhi T, Al Jashnmi RN, Al Khaduri M, Gowri V. Prevalence of tubal obstruction in the hysterosalpingogram of women with primary and secondary infertility. J Reprod Infertil. 2013;14(4):214-216.

18. Al-Turki H, Gullenpet A, Syed A, Al-Saif H, Aldhafery B. Uterine and tubal abnormalities in infertile Saudi Arabian women: a teaching hospital experience. Saudi J Med Med Sci. 2016;4(2):89-92.

19. Lim CP, Hasafa Z, Bhattacharya S, Maheshwari A. Should a hysterosalpingogram be a first-line investigation to diagnose female tubal subfertility in the modern subfertility workup? Hum Reprod. 2011; 26(5):967-971.

20. den Hartog JE, Lardenoije CM, Severens JL, Land JA, Evers JL, Kessels AG. Screening strategies for tubal factor subfertility. Hum Reprod. 2008;23(8):1840-1848.

21. Broeze KA, Opmeer BC, Coppus SF, et al. Chlamydia antibody testing and diagnosing tubal pathology in subfertile women: an individual patient data meta-analysis. Hum Reprod Update. 2011;17(3):301-310.

22. Ahmad G, Watson AJ, Metwally M. Laparoscopy or laparotomy for distal tubal surgery? A meta-analysis. Hum Fertil. 2007;10(1):43-47.

23. Swart P, Mol BW, van der Veen F, van Beurden M, Redekop WK, Bossuyt PM. The accuracy of hysterosalpingography in the diagnosis of tubal pathology: a meta-analysis. Fertil Steril. 1995;64(3):486-491.

24. Speroff L, Fritz MA. Clinical gynecologic endocrinology and infertility. 8th ed. Philadelphia, PA: Lippincott Williams \& Wilkins; 2011:1177-1179.

25. Ngowa JD, Kasia JM, Georges NT, Nkongo V, Sone C, Fongang E. Comparison of hysterosalpingograms with laparoscopy in the diagnostic of tubal factor of female infertility at the Yaoundé General Hospital, Cameroon. Pan Afr Med J. 2015;22:264.

26. Schankath AC, Fasching N, Urech-Ruh C, Hohl MK, Kubik-Huch RA. Hysterosalpingography in the workup of female infertility: indications, technique and diagnostic findings. Insights Imaging. 2012;3(5): 475-483.

27. Maheux-Lacroix S, Boutin A, Moore L, et al. Hysterosalpingosonography for diagnosing tubal occlusion in subfertile women: a systematic review with meta-analysis. Hum Reprod. 2014;29(5):953-963.

28. Verhoeve HR, Coppus SF, van der Steeg JW, et al. Collaborative Effort on the Clinical Evaluation in Reproductive Medicine. The capacity of hysterosalpingography and laparoscopy to predict natural conception. Hum Reprod. 2011;26(1):134-142.

29. Mol BW, Swart P, Bossuyt PM, van Beurden M, van der Veen F. Reproducibility of the interpretation of hysterosalpingography in the diagnosis of tubal pathology. Hum Reprod. 1996;11(6):1204-1208.

30. Mohiyiddeen L, Hardiman A, Fitzgerald C, et al. Tubal flushing for subfertility. Cochrane Database Syst Rev. 2015;(5):CD003718.

31. Kodaman PH, Arici A, Seli E. Evidence-based diagnosis and management of tubal factor infertility. Curr Opin Obstet Gynecol. 2004;16(3): 221-229.

32. La Fianza A, Dellafiore C, Travaini D, et al. Effectiveness of a single education and counseling intervention in reducing anxiety in women undergoing hysterosalpingography: a randomized controlled trial. ScientificWorldJournal. 2014.

33. Hindocha A, Beere L, O'Flynn H, Watson A, Ahmad G. Pain relief in hysterosalpingography. Cochrane Database Syst Rev. 2015;9: CD006106.

34. Kalantari M, Zadeh Modares S, Ahmadi F, et al. Randomized doubleblind clinical trial of eutectic mixture of local anesthetic creams in reducing pain during hysterosalpingography. Iran J Radiol. 2014;11(4): e10513.

35. Dreyer K, van Rijswijk J, Mijatovic V, et al. Oil-based or water-based contrast for hysterosalpingography in infertile women. $N$ Engl $J$ Med. 2017;376(21):2043-2052. 
International Journal of Women's Health

\section{Dovepress}

\section{Publish your work in this journal}

The International Journal of Women's Health is an international, peerreviewed open-access journal publishing original research, reports, editorials, reviews and commentaries on all aspects of women's healthcare including gynecology, obstetrics, and breast cancer. The Visit http://www.dovepress.com/testimonials.php to read real quotes from published authors.

manuscript management system is completely online and includes

Submit your manuscript here: http://www.dovepress.com/international-journal-of-womens-health-journal 